\title{
Poly(amido amine) dendrimer and silver nanoparticle-multi-walled carbon nanotubes composite with poly(neutral red)-modified electrode for the determination of ascorbic acid
}

\author{
C LAKSHMI DEVI and S SRIMAN NARAYANAN* \\ Department of Analytical Chemistry, School of Chemical Sciences, University of Madras, Guindy Campus, \\ Chennai 600 025, Tamil Nadu, India \\ *Author for correspondence (sriman55@gmail.com)
}

MS received 6 June 2018; accepted 26 September 2018; published online 6 March 2019

\begin{abstract}
A new film containing poly(amido amine) dendrimer, silver nanoparticles and multi-walled carbon nanotubes composite with poly(neutral red) was prepared on a paraffin wax impregnated graphite electrode. The PAMAM/AgNPsMWCNT/PNR film exhibited promising electrocatalytic oxidation of ascorbic acid (AA) in acetate buffer solution of $\mathrm{pH}$ 4.0. The PAMAM/AgNPs-MWCNT/PNR film-modified electrode enhanced the sensitivity of detection of AA. The PAMAM/AgNPs-MWCNT/PNR film-modified electrode was characterized by cyclic voltammetry, chronoamperometry, hydrodynamic voltammetry (HDV) and difference pulse voltammetry. These experiments confirmed the electrocatalytic oxidation of AA by PAMAM/AgNPs-MWCNT/PNR film-modified electrode. The PAMAM/AgNPs-MWCNT/PNRmodified electrode has been found to possess good electrocatalytic activity towards AA oxidation which has been observed at a lower oxidation potential of around $0.26 \mathrm{~V}$ with a higher current response. The electrochemical oxidation of AA by PAMAM/AgNPs-MWCNT/PNR-modified electrode involved a two proton and two electron process. A linear relationship between the catalytic current and AA concentration was obtained in the range from 0.16 to $2500 \mu \mathrm{M}$ with a detection limit of $0.053 \mu \mathrm{M}$.
\end{abstract}

Keywords. Dendrimer; ascorbic acid; nanoparticles; electrocatalytic oxidation.

\section{Introduction}

Ascorbic acid (AA), known as vitamin $\mathrm{C}$ is a water-soluble anti-oxidant present in foods, drinks, citrus fruits, vegetables and leafy vegetables. It is also important in several human, animal and plant metabolic processes involving oxidation and reduction. AA is a medication for scurvy, drug poisoning, liver disease, allergic reactions, atherosclerosis and it helps to promote healthy cell development, calcium absorption and normal tissue growth [1]. It is used for the prevention and treatment of the common cold, mental illness, infertility, cancer and AIDS [2]. Therefore, the detection of AA is of great importance in pharmaceutical, clinical and the food industry $[3,4]$. Several methods are available for the determination of AA, such as chemiluminescence [5], chromatography [6], titrimetry [7], enzymatic analysis [8] and electrochemical methods [9]. Electrochemical methods offer a series of advantages, such as rapid and sensitive response, ease of use and low cost. The development of electrodes for determination of AA in the presence of many interfering species has currently attracted considerable attention in the field of electroanalytical chemistry [10]. Electrochemical methods, especially various amperometric chemical sensors, have been extensively employed for the determination of AA. Various techniques and materials have been employed for the fabrication of chemical sensors including adsorption, crosslinking, layer-by-layer assembly, covalent binding, nanomaterials and so on $[11,12]$.

Carbon nanotubes (CNTs) are widely used in the fabrication of chemical sensors because of their high electrical conductivity, high chemical stability and extremely high mechanical strength [13]. In the last few decades, nanohybrid materials of CNTs with metal or metal oxide nanoparticles have received much attention. Due to their unique properties, these nanohybrid materials have been used in many applications such as chemical sensors, supercapacitor electrodes, catalyst support and antimicrobial therapies. The use of dendrimers as a binder to attach the metal and metal oxide nanoparticles on the surface of CNTs has also been reported [14]. Poly(amido amine) (PAMAM) dendrimers are unimolecular micelles having an amine $\left(-\mathrm{NH}_{2}\right)$ capped surface which attracts a carboxylic-acid capped pretreated graphite electrode surface $(-\mathrm{COOH})$.

In this work, we prepare and characterize a PAMAM dendrimer and AgNPs-MWCNTs composite with poly(neutral red) (PNR)-modified electrode as a working electrode for 
the determination of AA. Paraffin wax impregnated graphite electrode (PIGE) was used as a base electrode for this modification. PIGE is also a very useful carbon electrode with low background current, low noise and fast baseline stabilization [15]. The PAMAM/AgNPs-MWCNTs/PNRmodified electrode was studied by using several amperometric methods.

\section{Experimental}

\subsection{Chemicals and reagents}

Graphite rods (3 mm diameter) were purchased from Aldrich. Ethylenediamine and methyl acrylate were purchased from Merck. AA and neutral red (NR) were obtained from Sisco Research Laboratories, India. Sodium fluoride $(\mathrm{NaF})$ was purchased from Aldrich Chemicals. All the chemicals were of analytical grade and used as such without any further purification. All the supporting electrolytes $(0.1 \mathrm{M})$ and acetate buffer solution (ABS) were prepared with double distilled (DD) water.

\subsection{Apparatus}

The electrochemical experiments were carried out using CHI 400A and CHI 660B electrochemical system $(\mathrm{CH}$ instruments, USA). Cyclic voltammetry (CV) was performed using the conventional three-electrode system with the PAMAM/AgNPs-MWCNTs/PNR-modified electrode as the working electrode, a platinum wire as the counter electrode and standard calomel electrode as the reference electrode. The potential window for $\mathrm{CV}$ was from -1.0 to $1.0 \mathrm{~V}$ and the scan rate was $50 \mathrm{mV} \mathrm{s}^{-1}$. $\mathrm{pH}$ of the solution was measured using a digital $\mathrm{pH}$ meter (Digisun Electronics System). All experiments were performed at room temperature.

\subsection{Modification of PAMAM/AgNPs-MWCNTs/PNR film-modified electrode}

PAMAM dendrimer was synthesized as reported earlier [1618]. AgNPs were prepared as previously described [19]. The PIGE was prepared as reported earlier [20]. Graphite electrodes have a number of pores, which are modified when materials are easily absorbed inside the electrodes and become non-reusable. To avoid this condition, molten paraffin wax was used to fill the pores under vacuum conditions. The electrodes were taken out and solidified paraffin on the surface was removed by a knife. The polished circular end of the PIGE was immersed in $0.5 \mathrm{M} \mathrm{H}_{2} \mathrm{SO}_{4}$ solutions and a potential of $1.6 \mathrm{~V}$ was applied for $5 \mathrm{~min}$ to promote the carboxylic acid groups on the circular end surface of the PIG electrode. This is called as a pre-treated graphite electrode (PGE). The PGE was immersed in $0.1 \mathrm{M} \mathrm{NaF}$ solution containing PAMAM dendrimer $(1.6 \mu \mathrm{M})$ and electrochemically deposited on the surface of PIGE by applying a potential of $0.6 \mathrm{~V}$ for $1 \mathrm{~h}$. The PAMAM-coated electrode was taken out and allowed to dry at room temperature. The AgNPs-MWCNTs nanomaterials composite was prepared with $0.5 \times 10^{-4} \mathrm{M}$ MWCNTs dispersed in $100 \mu$ l of ethanol under ultrasonication for $30 \mathrm{~min}$. The MWCNTs (100 $\mu \mathrm{l})$ dispersion was mixed with $100 \mu \mathrm{l}$ of AgNPs, and the mixture was kept under ultrasonication for $1 \mathrm{~h}$ at room temperature. The MWCNTs nanomaterial composite was drop cast on the PAMAM-coated electrode surface and allowed to dry at room temperature. Then the PAMAM/AgNPs-MWCNTsmodified electrode was dipped in the $0.025 \mathrm{M}$ phosphate buffer solution (PBS) ( $\mathrm{pH} 5.5)+\mathrm{KNO}_{3}(0.1 \mathrm{M})$ solution containing $5 \times 10^{-4} \mathrm{M}$ NR. The NR was electropolymerized over the surface of PAMAM/AgNPs-MWCNTs-modified electrode by scanning the potential from -1.0 to $1.0 \mathrm{~V}$ for 20 cycles at a scan rate of $50 \mathrm{mV} \mathrm{s}^{-1}$. The resulting PAMAM/AgNPs-MWCNTs/PNR-modified electrode was used for the electrocatalytic oxidation of AA.

\section{Results and discussion}

\subsection{The polymerization of NR over the PAMAM/AgNPs-MWCNTs-modified electrode}

The electropolymerization of NR on the surface of PAMAM/AgNPs-MWCNTs-modified electrode was carried out by applying the potential of -1.0 to $1.0 \mathrm{~V}$ for 20 cycles (figure 1). The NR solution concentration was $5 \times 10^{-4}$ $\mathrm{M}$ in $0.025 \mathrm{M}$ PBS ( $\mathrm{pH} 5.5)+0.1 \mathrm{M} \mathrm{KNO}_{3}$. The addition of $0.1 \mathrm{M} \mathrm{KNO}_{3}$ to the supporting electrolyte was done as the catalytic effect of $\mathrm{NO}_{3}^{-}$anions was observed on the electropolymerization of phenazine and phenothiazine dyes [21-25]. The cyclic voltammograms showed two redox couples, the first redox couple around -0.45 and $-0.75 \mathrm{~V}$ due to the PNR film on PAMAM/AgNPs-MWCNTs-modified electrode and hence an increase in current and the second redox

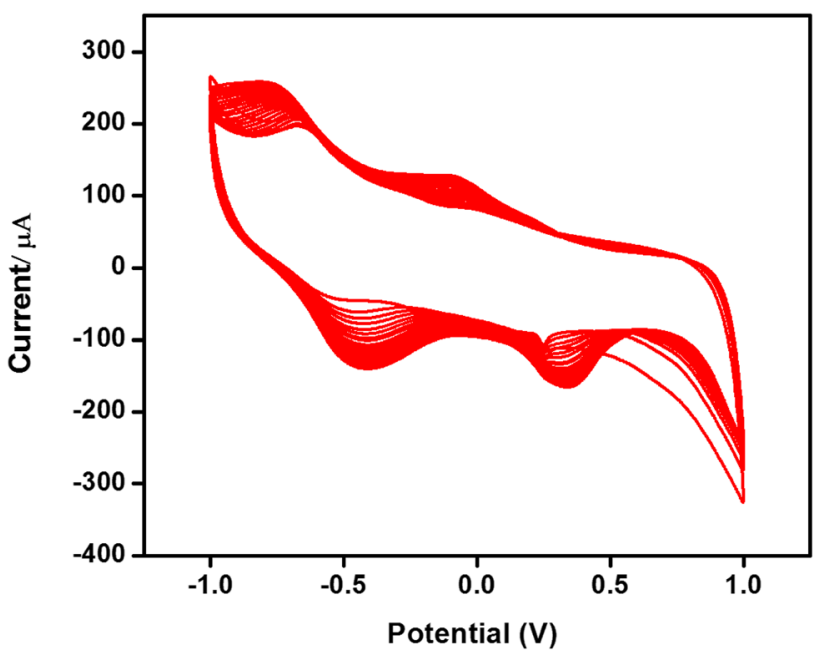

Figure 1. Electrochemical polymerization of NR $\left(5 \times 10^{-4} \mathrm{M}\right)$ in $0.05 \mathrm{M}$ PBS $(\mathrm{pH} 5.5)+1.0 \mathrm{M} \mathrm{KNO}_{3}$ at a scan rate of $50 \mathrm{mV} \mathrm{s}^{-1}$. 

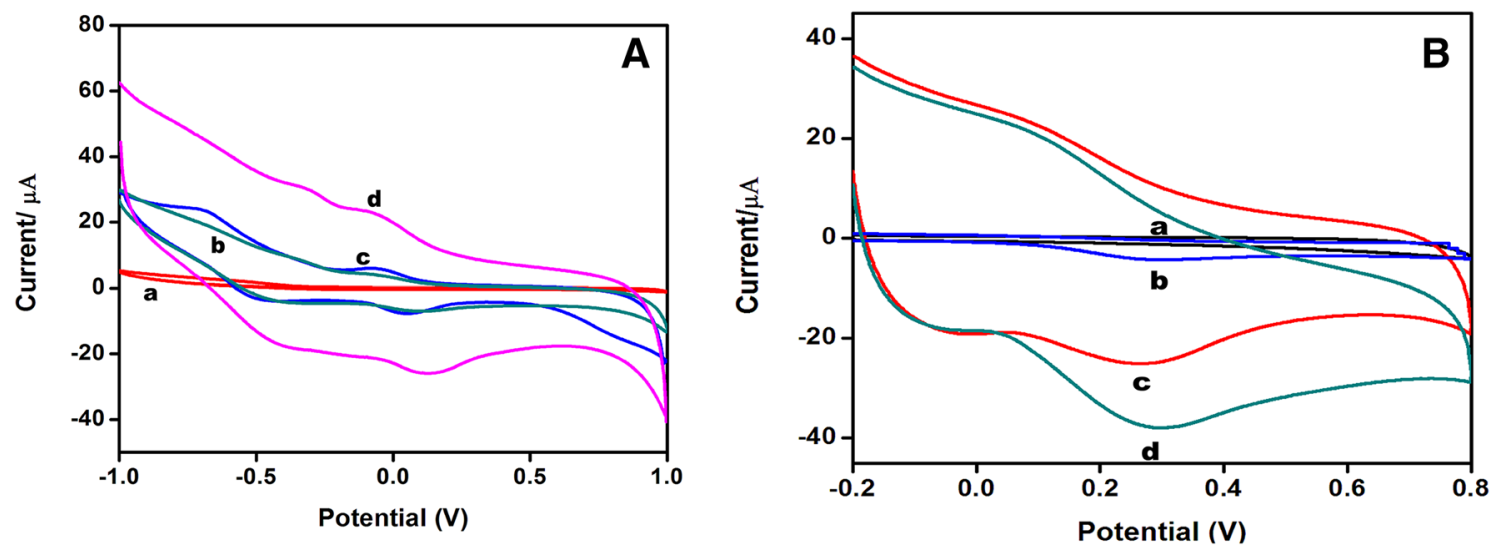

Figure 2. (A) CVs of bare PIGE (curve a), PAMAM/AgNPs (curve b), PAMAM/AgNPs/MWCNTs-modified electrode (curve c) and PAMAM/AgNPs/MWCNTs/PNR-modified electrode (curve d) in $0.1 \mathrm{M} \mathrm{ABS} \mathrm{of} \mathrm{pH} 4.0$ at a scan rate of $50 \mathrm{mV} \mathrm{s}^{-1}$. (B) CVs of bare and PAMAM/AgNPs-MWCNT/PNR-modified electrode in the absence (a, c) and in the presence $(\mathrm{b}, \mathrm{d})$ of $163 \mu \mathrm{M}$ of AA in $0.1 \mathrm{M} \mathrm{ABS}$ of $\mathrm{pH} 4.0$ at a scan rate of $50 \mathrm{mV} \mathrm{s}^{-1}$.

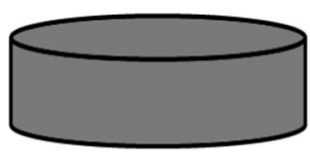

Bare(PIGE)

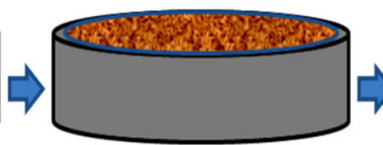

Pretreated graphite electrode (PIGE)

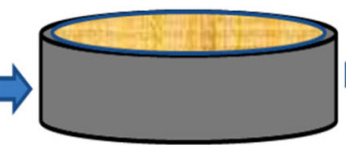

PAMAM Dendrimer coated electrode

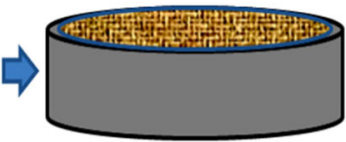

PAMAM/AgNPs-MWCNTs coated electrode
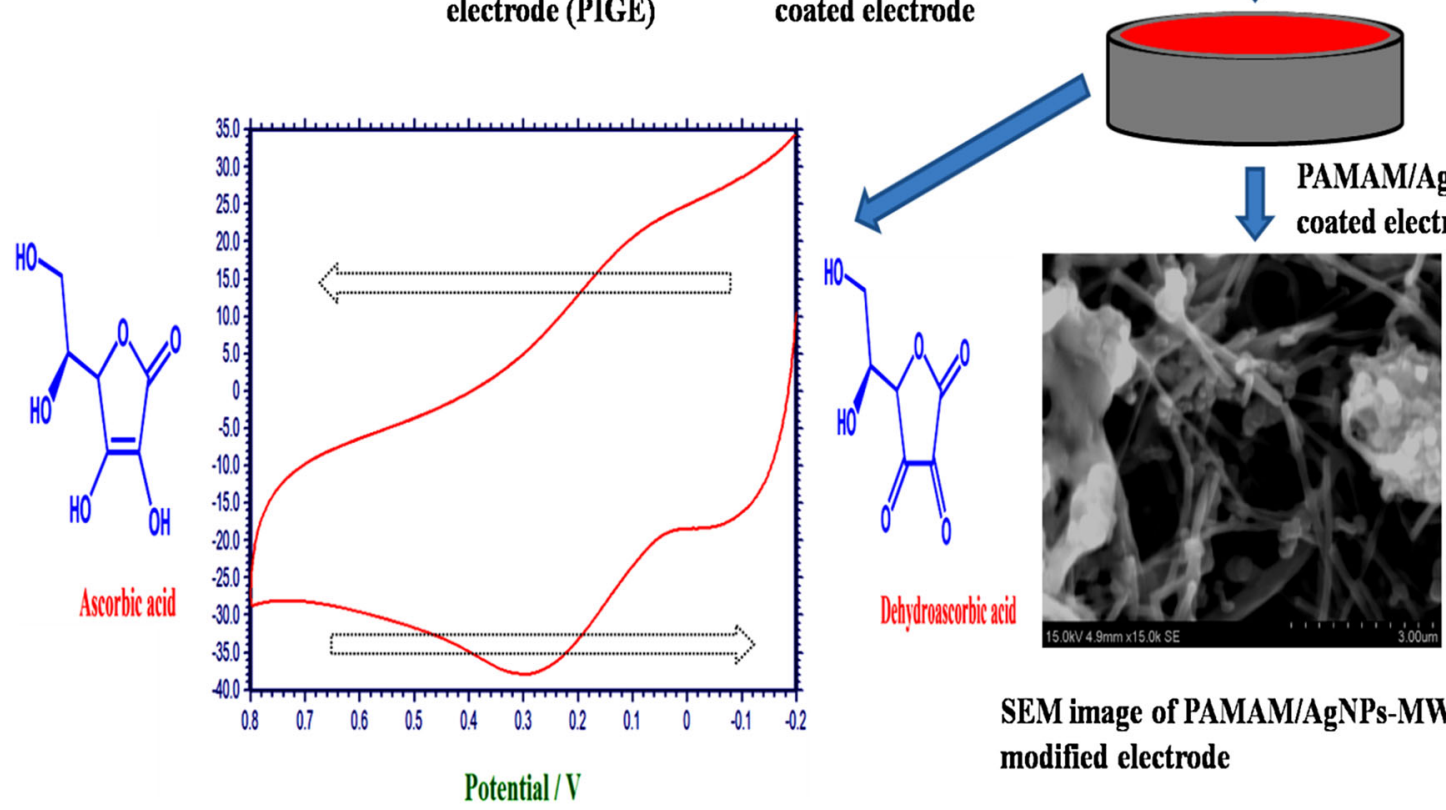

SEM image of PAMAM/AgNPs-MWCNTs/PNR modified electrode

Electrochemical mechanism of ascorbic acid

Scheme 1. The illustration of electrode preparation and mechanism of PAMAM/AgNPs-MWCNTs/PNR-modified electrode towards the determination of AA.

couple around 0.33 and $-0.09 \mathrm{~V}$ corresponding to doping and de-doping of the polymer, increasingly broadening with the number of cycles. The irreversible oxidation peak of NR monomer was observed at $0.9 \mathrm{~V}$ [22]. However, in neutral solutions, the oxidized NR released a proton which makes it uncharged and thus slightly soluble. In order to achieve a balance between these opposing tendencies, pH 5.5 was chosen for electropolymerization [23]. The peak current at $-0.45 \mathrm{~V}$ 
increased for successive cycles due to the growth of the PNR films over the surface of PAMAM/AgNPs-MWCNTsmodified electrode. Once the polymer film was formed, the PAMAM/AgNPs-MWCNTs/PNR electrode was dipped in $0.1 \mathrm{M}$ ABS of $\mathrm{pH} 7$ and scanned at a potential range from -1.0 to $1.0 \mathrm{~V}$ to confirm the formation of polymer film and stability.

\subsection{Electrochemical behaviour of the \\ PAMAM/AgNPs-MWCNT/PNR-modified electrode}

The cyclic voltammetric investigation of the bare electrode (curve a), PAMAM/AgNPs electrode (curve b), PAMAM/ AgNPs/MWCNTs electrode (curve c) and PAMAM/AgNPs / MWCNTs/PNR-modified electrode (curve d) are shown in figure 2A. The PAMAM/AgNPs electrode (curve b), PAMAM/AgNPs/MWCNTs electrode (curve c) showed a very lower current response and the oxidation and reduction peak occurred due to the AgNPs. The cyclic voltammetric response of the bare electrode did not show any characteristic peak (curve a). The electrochemical response of PAMAM/AgNPs-MWCNTs/PNR-modified electrode in the presence of AA was investigated by $\mathrm{CV}$, chronoamperometry (CA), hydro-dynamic voltammetry (HDV) and differential pulse voltammetry (DPV). Figure $2 \mathrm{~B}$ illustrates the CVs of bare (a) and PAMAM/AgNPs-MWCNT/PNR-modified in the absence (c) and presence (b, d) of $163 \mu \mathrm{M}$ AA. The bare PIGE oxidized AA at $0.4 \mathrm{~V}$ but the PAMAM/ AgNPs-MWCNTs/PNR-modified electrode oxidized at a very low potential of around $0.26 \mathrm{~V}$. The PAMAM/AgNPsMWCNTs/PNR-modified electrode showed an anodic peak $\left(E_{\mathrm{pa}}\right)$ and cathodic peak $\left(E_{\mathrm{pc}}\right)$ at 0.26 and $0.07 \mathrm{~V}$ respectively, and a formal potential $E^{\circ}\left[E^{\circ}=\left(E_{\mathrm{pa}}+E_{\mathrm{pc}}\right) / 2\right]$ of $0.16 \mathrm{~V}$. The value of $\Delta E_{\mathrm{p}}$ was $\left[\Delta E_{\mathrm{p}}=E_{\mathrm{pa}}-E_{\mathrm{pc}}\right]$ $0.19 \mathrm{~V}$. Therefore, due to the effect of background electrolyte, pH-modified electrode oxidizes AA at very low potential and the peak current is higher when compared with bare PIGE. This is due to the presence of PNR film incorporated with AgNPs-MWCNTs and PAMAM, which enhances the electrocatalytic activity of the electrode towards the oxidation of AA. Scheme 1 shows a possible mechanism for the electrocatalytic oxidation of PAMAM/AgNPs-MWCNTs/PNR-modified electrode in the presence of AA.
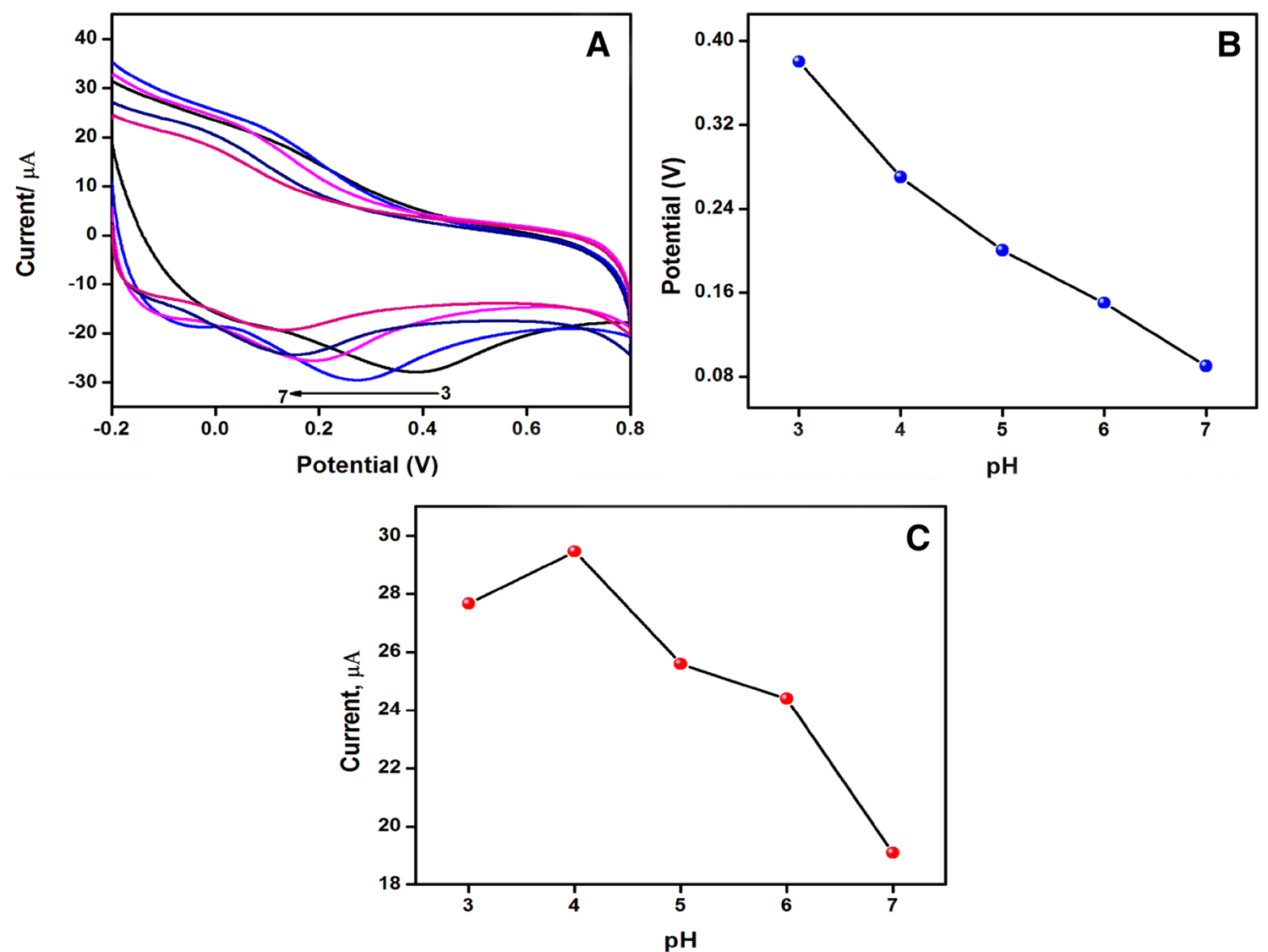

Figure 3. (A) Cyclic voltammograms of PAMAM/AgNPs-MWCNTs/PNR-modified electrode containing $81.5 \mu \mathrm{M}$ AA in ABS at different $\mathrm{pH}(\mathrm{pH} 3-7)$. (B) The calibration plot of potential response vs. $\mathrm{pH}$. (C) The calibration plot of current response $v s$. $\mathrm{pH}$. 


\subsection{Effect of supporting electrolyte and $\mathrm{pH}$}

Cyclic voltammetric methods were carried out to find a favourable supporting electrolyte for the PAMAM/AgNPsMWCNTs/PNR-modified electrode. The PAMAM/AgNPsMWCNTs/PNR-modified electrode was scanned between -0.2 and $0.8 \mathrm{~V}$ in $0.1 \mathrm{M}$ of various electrolyte solutions such as $\mathrm{KNO}_{3}, \mathrm{NaCl}, \mathrm{KCl}, \mathrm{NaNO}_{3}, \mathrm{NaOH}, \mathrm{NH}_{4} \mathrm{Cl}$ and ABS. The ABS presents an excellent response towards the redox reactions of PAMAM/AgNPs-MWCNTs/PNRmodified electrode and hence ABS was chosen as the supporting electrolyte for further electrochemical studies. To between peak potential and $\mathrm{pH}$ is given by the following equation:

$$
\mathrm{d} E_{\mathrm{pa}} / \mathrm{dpH}=2.303 m R T / n F
$$

where $m$ is the number of protons, $n$ is the number of electrons and $F, R$ and $T$ have their standard meanings. The proportion of the electrons and protons involved in the electrocatalytic oxidation of AA is $1: 1$. The number of protons involved in the reaction was calculated to be 2 . The possible mechanism for the catalytic oxidation is as shown below.

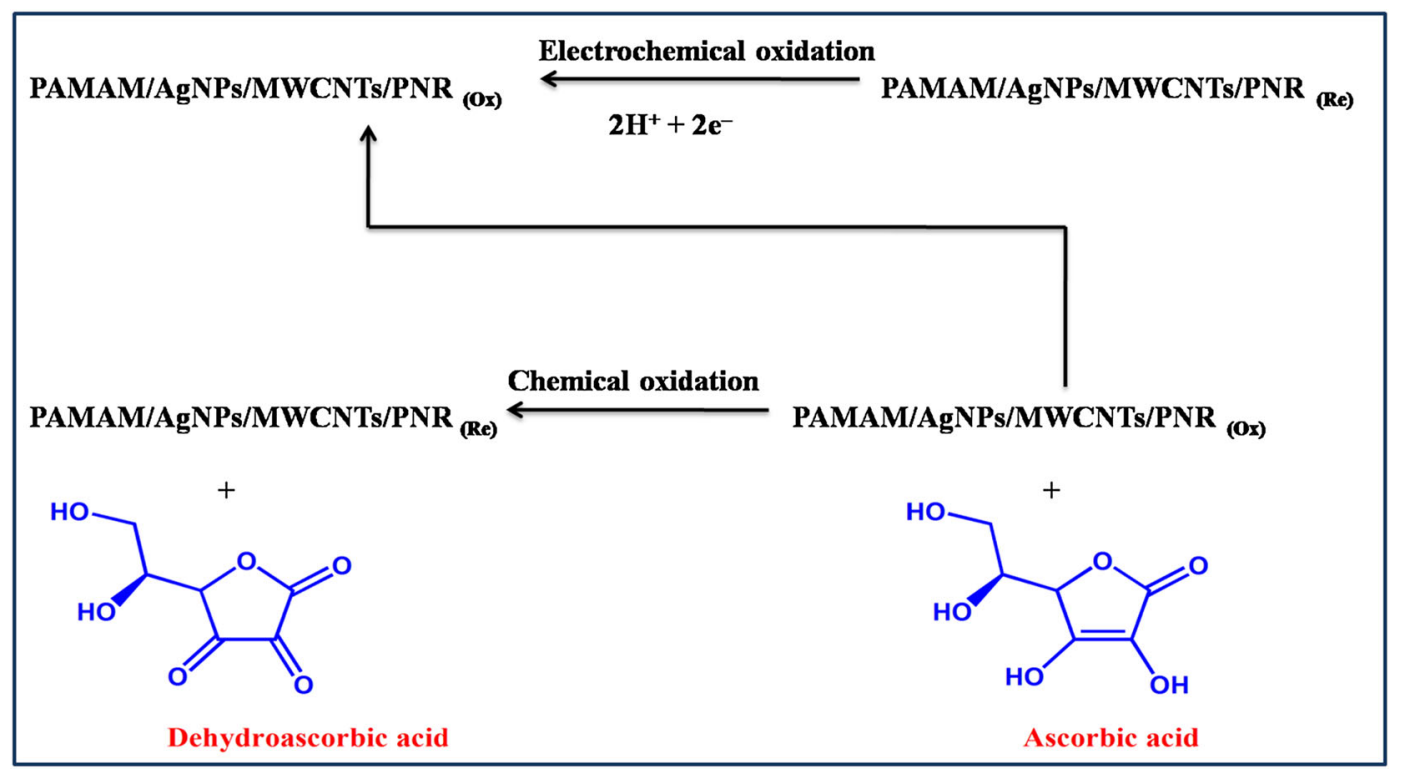

study the effect of $\mathrm{pH}$ of PAMAM/AgNPs-MWCNTs/PNRmodified electrode in the presence of AA $(81.5 \mu \mathrm{M})$, the $\mathrm{pH}$ of $\mathrm{ABS}$ was varied from 3 to 7 (figure $3 \mathrm{~A}$ ). The voltammetric results collected from -0.2 to $0.8 \mathrm{~V}$ display reversible oxidation and reduction peaks. It is also observed that the peak current decreases as $\mathrm{pH}$ increases from 5-7. The influence of $\mathrm{pH}$ on the peak current of AA has shown that it reached a maximum at ABS $\mathrm{pH}$ 4. Furthermore, the maximum oxidation current may be observed at $\mathrm{pH} 4.0$ because of the effective interaction between PAMAM/AgNPs-MWCNTs/PNR and AA, so pH 4 was chosen as an optimized $\mathrm{pH}$ value for the electrochemical determination of AA. When the $\mathrm{pH}$ value of electrolyte is $>5$, it may affect the sensitivity and conductivity of PAMAM/AgNPs-MWCNTs/PNR at the modified electrode surface. Figure $3 \mathrm{~B}$ shows the calibration plot of potential response $v s . \mathrm{pH}$ and figure $3 \mathrm{C}$ shows the calibration plot of current response vs. $\mathrm{pH}$. The $\mathrm{pH} v s$. peak potential corresponding linear equation is $E_{\mathrm{pa}}(\mathrm{V})=(0.568 \pm$ $0.07) x+(0.033 \pm 0.006)\left(R^{2}=0.978\right)$. The correlation 3.3a Mechanism: The active surface concentration $(\Gamma)$ PAMAM/AgNPs-MWCNTs/PNR-modified electrode was calculated by the following equation:

$$
\Gamma=\frac{Q}{n F A} .
$$

The CVs response of PAMAM/AgNPs/MWCNTs/PNRmodified electrode (curve c) at the scan rate of $50 \mathrm{mV} \mathrm{s}^{-1}$ was used to obtain the charge $(Q)$. The obtained values have been substituted in the equation given above, where $n$ is the number of electron transfer $(n=2), A$ is the electrode surface area $\left(A=0.07 \mathrm{~cm}^{2}\right)$ and $F, R$ and $T$ have their standard meanings. The value of $\Gamma$ was calculated to be $3.0989 \times 10^{-10} \mathrm{~mol} \mathrm{~cm}{ }^{-2}$. The redox activity of the PNR on PAMAM/AgNPs/MWCNTs is an electrochemical process that involves two electrons and two protons per site according to the following equation:

$$
I_{\mathrm{p}}=\frac{Q n F v}{4 R T}
$$



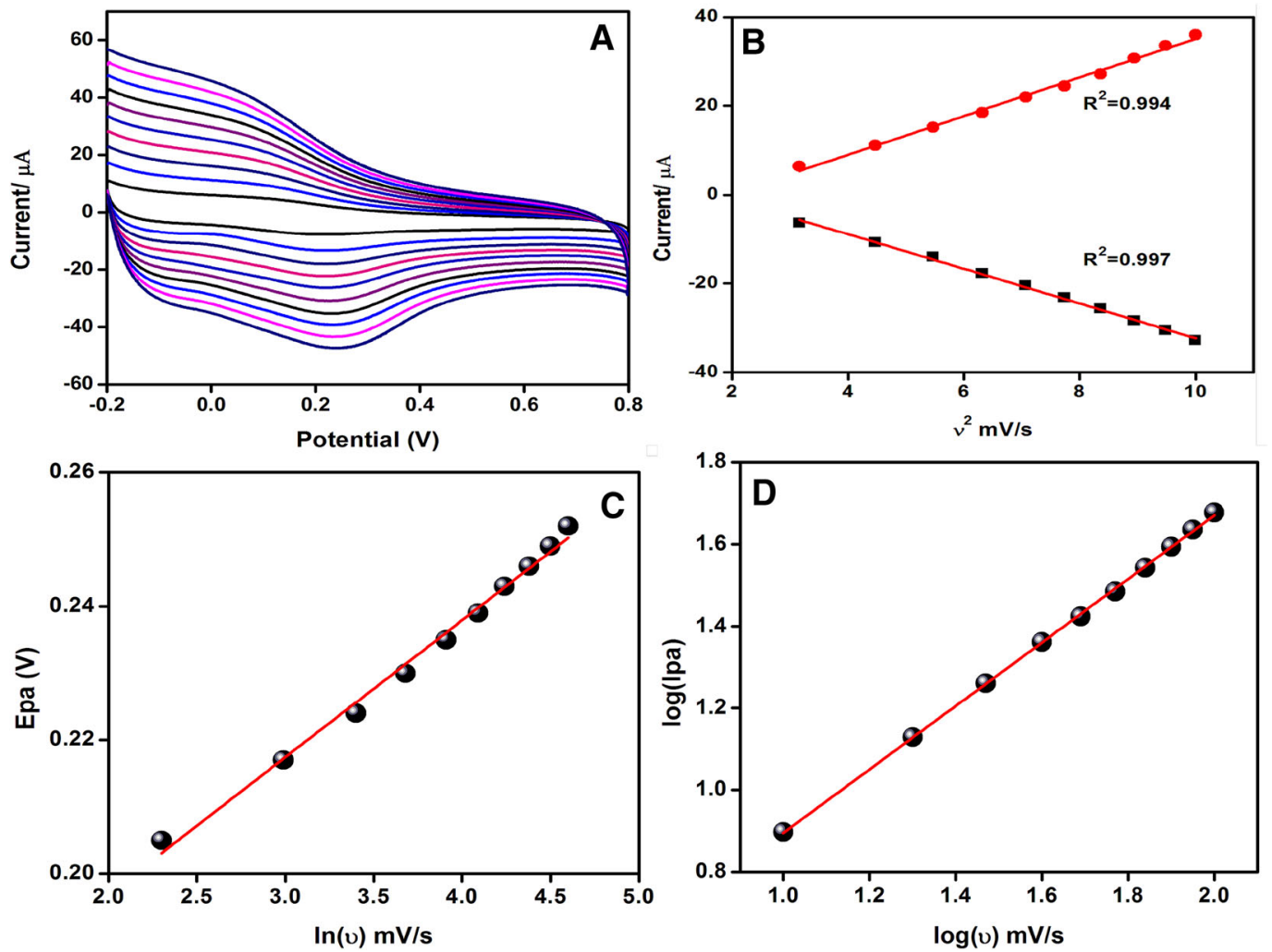

Figure 4. (A) Cyclic voltammograms of $81.5 \mu \mathrm{M}$ AA at PAMAM/AgNPs-MWCNTs/PNR-modified electrode at different scan rates $\left(10,20,30,40,50,60,70,80,90\right.$ and $\left.100 \mathrm{mV} \mathrm{s}^{-1}\right)$ in $0.1 \mathrm{M} \mathrm{ABS}$ of pH 4.0. (B) Relationship between anodic peak current, cathodic peak current and square root of scan rate. (C) Relationship between anodic peak potential and ln scan rate. (D) Relationship between logarithmic anodic peak current and logarithmic scan rate.

where $I_{\mathrm{p}}=$ peak current $(\mu \mathrm{A}), A=$ surface area of the electrode $\left(\mathrm{cm}^{2}\right)$ and $v=$ scan rate $\left(\mathrm{mV} \mathrm{s}^{-1}\right) . F, R$ and $T$ have their standard meanings.

\subsection{Effect of scan rate}

In order to study the nature of the electrode process at the PAMAM/AgNPs-MWCNTs/PNR-modified electrode surface, CVs were recorded at different scan rates. Figure 4A shows the CVs corresponding to $81.5 \mu$ M AA using PAMAM/ AgNPs-MWCNTs/PNR-modified electrode at different scan rates $\left(10,20,30,40,50,60,70,80,90\right.$ and $\left.100 \mathrm{mV} \mathrm{s}^{-1}\right)$ in $0.1 \mathrm{M}$ ABS of $\mathrm{pH}$ 4.0. It has been observed that the oxidation and reduction peak current increased linearly with increase in scan rate. Figure 4B illustrates the relationship between anodic peak current, cathodic peak current $v s$. square root of scan rate. The $I_{\mathrm{pa}}$ and $I_{\mathrm{pc}}$ increased linearly with $\left(v^{1 / 2}\right)$, and the corresponding regression equation was $I_{\mathrm{pa}}=(6.707 \pm 3.903) x+(0.46 \pm 0.06)\left(R^{2}=0.997\right)$ and $I_{\mathrm{pc}}=(-8.366 \pm 4.348) x+(0.82 \pm 0.11)\left(R^{2}=0.994\right)$ for anodic and cathodic scans respectively. Figure $4 \mathrm{C}$ and $\mathrm{D}$ illustrates the relationship between anodic peak potential
$\left(E_{\mathrm{pa}}\right) v s . \ln$ scan rate $(\ln v)$ and $\log$ anodic peak current $\left(\log I_{\mathrm{pa}}\right) v s . \log$ scan rate $(\log v)$ respectively. Figure $4 \mathrm{C}$ shows $E_{\mathrm{pa}}$ increased linearly with ( $\left.\ln v\right)$, and the corresponding regression equation was $E_{\mathrm{pa}}(\mathrm{V})=(0.155 \pm 0.020) x+$ $(0.002 \pm 6.013)\left(R^{2}=0.9923\right)$. The relationship between $E_{\mathrm{pa}} v s . \log (v)$ for analytical oxidation peak is studied and observed that, as the scan rate increases, the peak potential shifts to a more positive value. A linear relationship is observed in the range $10-100 \mathrm{mV} \mathrm{s}^{-1}$. A linear relationship is observed between $\log I_{\mathrm{pa}}$ and $\log v$ and the corresponding equations and correlation coefficients are expressed for $I_{\mathrm{pa}}=(0.120 \pm 0.775) x+(0.008 \pm 0.005)\left(R^{2}=0.9996\right)$. Figure 4D shows a double logarithmic plot of $\log (v) v s$. $\log \left(I_{\mathrm{pa}}\right)$, from which the slope value was found to be 0.77 resembling an electron transfer process that is adsorption controlled. The relationship between $\ln (v)$ and $E_{\mathrm{pa}}(\mathrm{V})$ can be expressed as Laviron equation [26]:

$$
E_{\mathrm{pa}}=E^{\circ}-\frac{R T}{(1-\alpha) n F} \ln \frac{R T K_{\mathrm{s}}}{(1-\alpha) n F}+\frac{R T}{(1-\alpha) n F} \ln v
$$



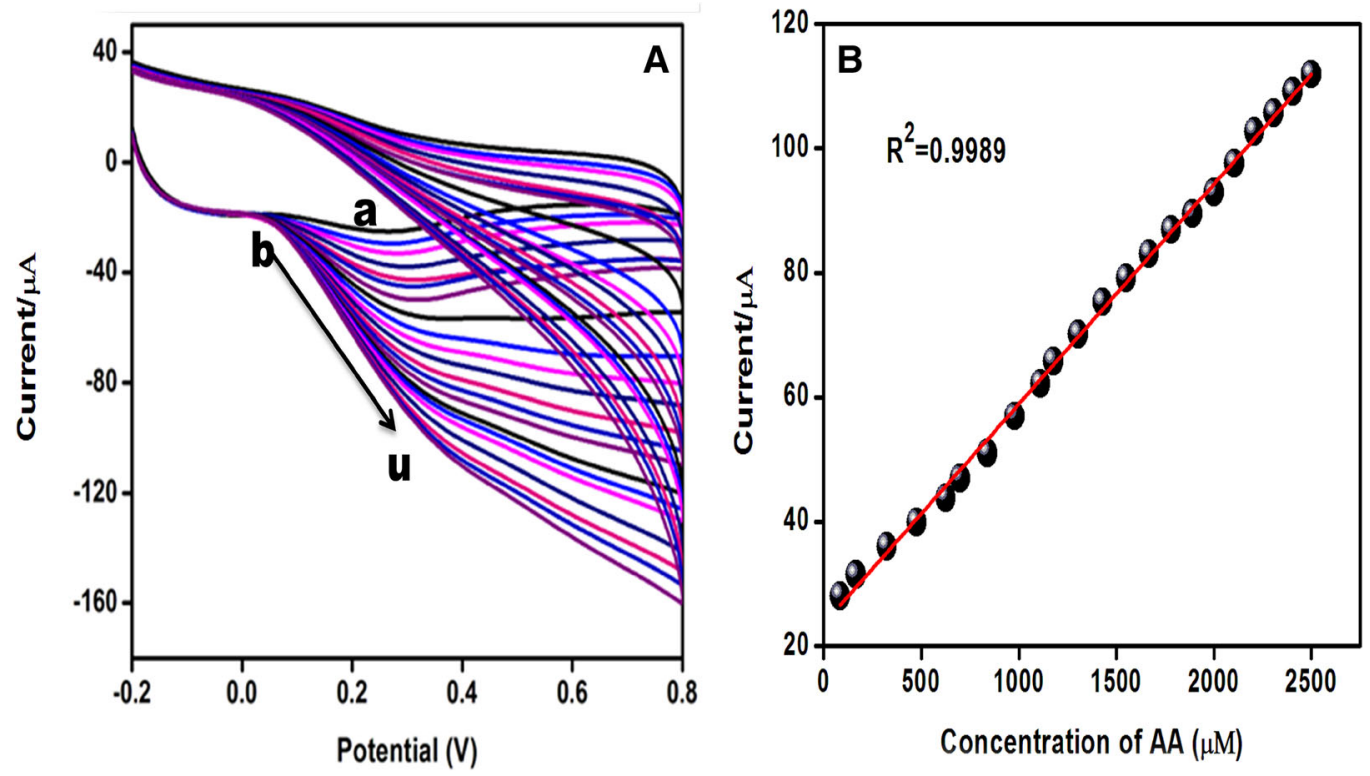

Figure 5. (A) CV response of PAMAM/AgNPs-MWCNT/PNR-modified electrode in the absence (a) and in the presence $(\mathrm{b}-\mathrm{u})$ of successive additions of $\mathrm{AA}(81.5$ to $2500 \mu \mathrm{M})$ in $0.1 \mathrm{M} \mathrm{ABS}$ of $\mathrm{pH} 4$ at the scan rate of $50 \mathrm{mV} \mathrm{s}^{-1}$. (B) The calibration plot of current response $v s$. concentration of AA.

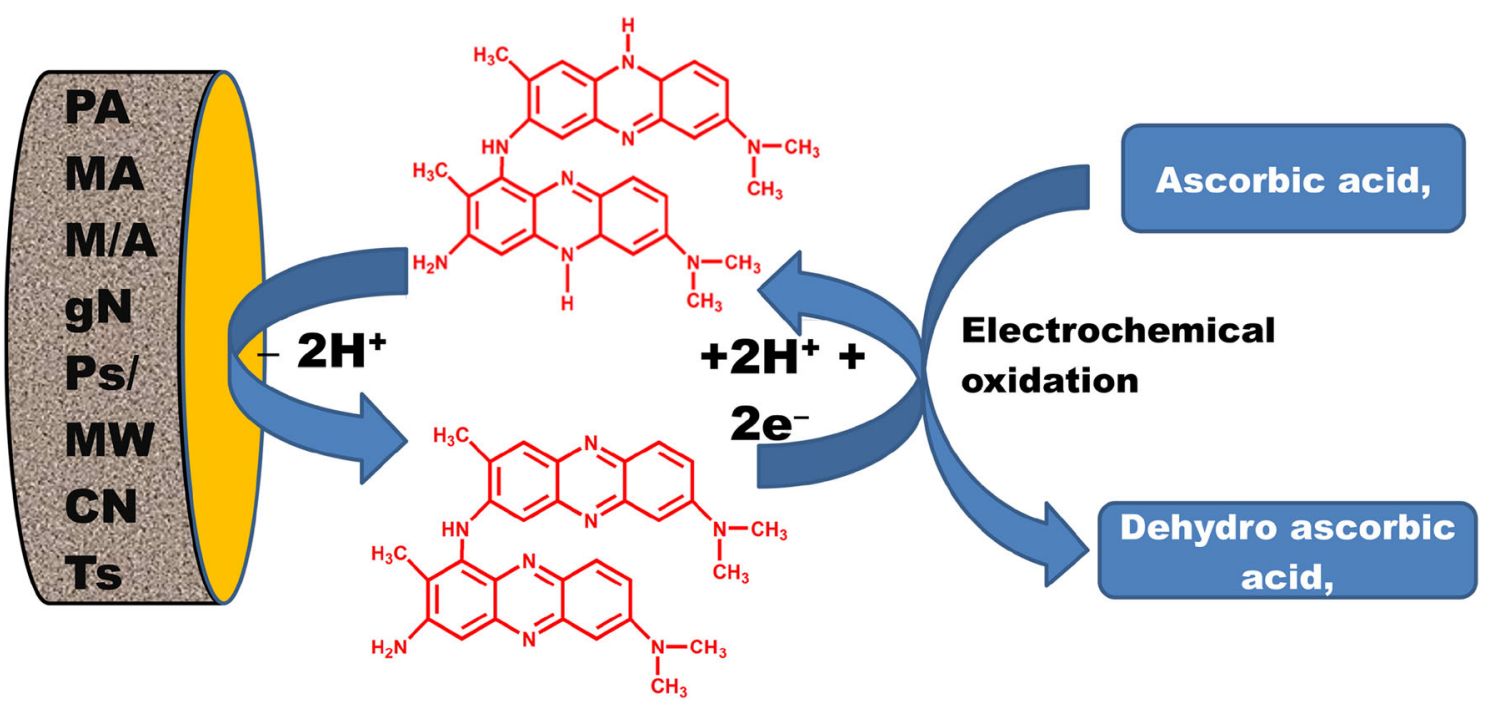

Scheme 2. PAMAM/AgNPs-MWCNTs/PNR-modified electrode electrocatalytic oxidation with AA.

where $\alpha$ is the charge transfer coefficient; $v$ is the scan rate in $\mathrm{mV} \mathrm{s}^{-1} ; n$ is the number of electrons transferred; $K_{\mathrm{S}}$ is the electron transfer rate constant; and $R, T$ and $F$ have their standard meanings [27]. The value of $\alpha=0.61$ was calculated from the slope of $\log (v) v s . \log \left(I_{\mathrm{pa}}\right)$ which indicates a reversible electrode process. Substituting the Laviron equation, the $K_{\mathrm{s}}$ for the electrochemical reaction involving PAMAM/AgNPs-MWCNTs/PNR-modified electrode was calculated to be $0.17 \mathrm{~s}^{-1}$.

\subsection{Electrochemical oxidation of AA by PAMAM/AgNPs-MWCNT/PNR-modified electrode}

Figure 5A shows the CVs responses of PAMAM/ AgNPs-MWCNTs/PNR-modified electrode on different concentrations of AA. Curves b to u represent the presence of AA from 81.5 to $2500 \mu \mathrm{M}$ at the potential ranging from -0.2 to $0.8 \mathrm{~V}$ in $0.1 \mathrm{M} \mathrm{ABS}$ of $\mathrm{pH} 4$ at a scan rate of $50 \mathrm{mV} \mathrm{s}^{-1}$. Figure 5B shows the calibration plot of current 


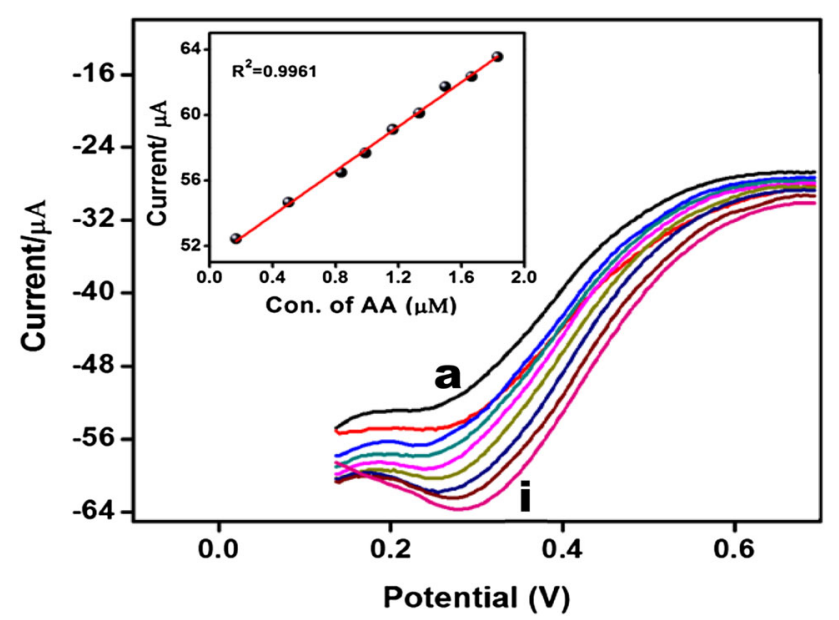

Figure 6. DPV response of PAMAM/AgNPs-MWCNT/PNRmodified electrode in the presence (a-i) of successive additions of AA $(0.16-1.6 \mu \mathrm{M})$ in $0.1 \mathrm{M} \mathrm{ABS}$ of $\mathrm{pH} 4$ at the scan rate of 50 $\mathrm{mV} \mathrm{s}^{-1}$. The insert shows the calibration plot of current response $v s$. concentration of AA in the range of $0.16-1.6 \mu \mathrm{M}$.

response vs. concentration of AA. By increasing the concentration of AA, the oxidation current also increased linearly and a correlation coefficient was 0.9989. Scheme 2 shows the redox features of the PAMAM/AgNPs-MWCNTs/PNRmodified electrode.

\subsection{Differential pulse voltammetry}

In order to improve the sensitivity for the electrocatalytic oxidation of AA, DPV has been employed to record the oxidation current of the PAMAM/AgNPs-MWCNTs/PNRmodified electrode. Figure 6 shows the DPV measurements of
PAMAM/AgNPs-MWCNTs/PNR-modified electrode in the presence of different concentrations of AA in ABS ( $\mathrm{pH} 4.0)$. The DPV response of the AA increased with increasing concentration. A linear relationship was obtained between the peak currents and the concentration of AA over the range from 0.16 to $1.6 \mu \mathrm{M}$ (inset). The corresponding linear regression equation is $I_{\mathrm{pa}}(\mu \mathrm{A})=(0.317 \pm 0.061) x+(8.957 \pm$ 8.548) $\left(R^{2}=0.9961\right)$. The limit of detection of AA was determined to be $0.053 \mu \mathrm{M}$. These results clearly indicate that PAMAM/AgNPs-MWCNTs/PNR-modified electrode has excellent capacity for the determination of AA. The proposed method is compared with already reported methods and the comparative results are shown in table 1.

\subsection{Determination of AA under dynamic conditions}

The applicability of PAMAM/AgNPs-MWCNTs/PNRmodified electrode for determination of AA in the flow system was evaluated by performing hydrodynamic voltammogram studies. Figure 7 shows the hydrodynamic voltammograms of bare PIG electrode (a) and PAMAM/ AgNPs-MWCNTs/PNR-modified electrode (b) in the presence of $81.5 \mu \mathrm{M}$ AA (curve a and $b$ respectively) in ABS of $\mathrm{pH} 4$ at a scan rate of $50 \mathrm{mV} \mathrm{s}^{-1}$ under stirring rate of $300 \mathrm{rpm}$. The results of hydrodynamic voltammogram studies showed a good response of PAMAM/AgNPs-MWCNTs/PNRmodified electrode at $0.25 \mathrm{~V}$ (curve b). The results indicated the fact that the electrocatalytic oxidation of AA by the PAMAM/AgNPs-MWCNTs/PNR-modified electrode was favoured even in the dynamic conditions. The hydrodynamic voltammogram studies of the bare PIG electrode (curve a) did not show any considerable current response compared to the PAMAM/AgNPs-MWCNTs/PNR-modified electrode (curve b) under similar conditions.

Table 1. Comparison of electrochemical detection of AA using different types of modified electrodes.

\begin{tabular}{|c|c|c|c|c|c|}
\hline Electrode & Electrolyte $\mathrm{pH}$ & Technique & $\begin{array}{c}\text { Linear range } \\
\left(\mu \mathrm{mol} 1^{-1}\right)\end{array}$ & $\begin{array}{c}\text { LOD } \\
\left(\mu \mathrm{mol} \mathrm{1} 1^{-1}\right)\end{array}$ & Reference \\
\hline $\mathrm{Pd}-\mathrm{CNFs} / \mathrm{CPE}$ & $0.1 \mathrm{M}$ PBS pH 4.5 & DPV & $50-4000$ & 15 & {$[28]$} \\
\hline ERGO/GCE & $0.1 \mathrm{M}$ PBS pH 7.0 & DPV & $500-2000$ & 250 & [29] \\
\hline $\mathrm{Pd}_{3} \mathrm{Pt} 1 / \mathrm{PDDA}-\mathrm{RGO}$ & $0.1 \mathrm{M}$ PBS pH 7.4 & DPV & $40-1200$ & 0.61 & {$[30]$} \\
\hline $\mathrm{Au} @ \mathrm{Pd}-\mathrm{RGO} / \mathrm{GCE}$ & $0.1 \mathrm{M}$ PBS pH 7.0 & DPV & $0.1-1000$ & 0.02 & {$[31]$} \\
\hline Chitosan-graphene GCE & 0.05 M PBS pH 7.0 & DPV & $50-1200$ & 50 & {$[32]$} \\
\hline PTCA/PDAox/GC & 0.1 M PBS pH 3.0 & DPV & $76-3900$ & 25.3 & {$[33]$} \\
\hline $\mathrm{P}-4-\mathrm{ABA} / \mathrm{GCE}$ & $0.2 \mathrm{M}$ PBS pH 4.5 & DPV & $20-800$ & 5.0 & [34] \\
\hline Poly(Tyr)/MWCNTs-COOH/GCE & 0.067 M PBS pH 7.4 & DPV & $50-1000$ & 2.0 & {$[35]$} \\
\hline CPE/MWCNTs/IL/PdNPs & 0.1 M PBS pH 5.0 & DPV & $0.6-112$ & 0.200 & [36] \\
\hline PAMAM/AgNps & $0.1 \mathrm{M}$ PBS pH 4.0 & DPV & $17-1428$ & 5.5 & This work \\
\hline PAMAM/AgNPs-MWCNTs & $0.1 \mathrm{M}$ PBS pH 4.0 & DPV & $8-1895$ & 2.8 & This work \\
\hline PAMAM/AgNPs-MWCNTs/PNR & $0.1 \mathrm{M}$ PBS pH 4.0 & DPV & $0.2-2500$ & 0.053 & This work \\
\hline
\end{tabular}

Pd-CNFs/CPE: palladium nanoparticle-loaded carbon nanofibres, GCE: glassy carbon electrode, ERGO: reduced graphene oxide, $\mathrm{Pd}_{3}$ Pt1/PDDA-RGO: graphene anchored with Pd-Pt nanoparticles, Au@Pd-RGO: Au@Pd-reduced graphene oxide nanocomposites, PTCA/PDAox/GC: 3,4,9,10-perylenetetracarboxylic acid/oxidized dopamine polymer, P-4-ABA/GCE: poly(4-aminobutyric acid)-modified glassy carbon electrode, CPE/MWCNTs/IL/PdNPs: carbon paste electrode/multi-walled CNTs/ionic liquid/palladium nanoparticles. 


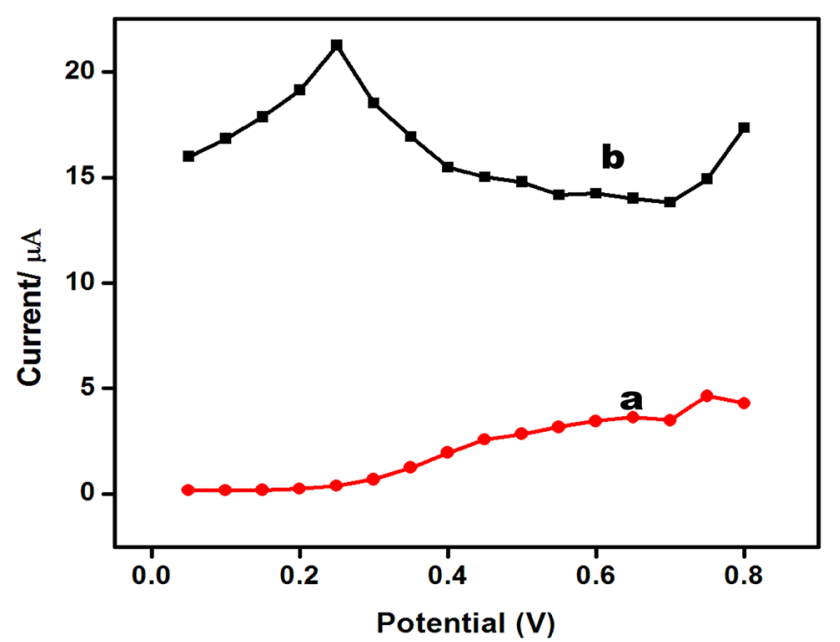

Figure 7. Hydrodynamic voltammograms of the bare (a) and PAMAM/AgNPs-MWCNTs/PNR-modified electrode (b), $0.1 \mathrm{M}$ ABS of $\mathrm{pH} 4.0$, in the presence of $81.5 \mu \mathrm{M}$ AA at a scan rate of $50 \mathrm{mV} \mathrm{s}^{-1}$ under stirring conditions.

\subsection{The amperometric response of the} PAMAM/AgNPS-MWCNTS/PNR-modified electrode

The PAMAM/AgNPs-MWCNTs/PNR-modified electrode has excellent and strong mediating properties and facilitates the low potential amperometric sensor for the determination of AA. Figure 8A shows the chronoamperometric response of AA and the oxidation of AA by PAMAM/AgNPsMWCNTs/PNR-modified electrode at a fixed potential of
$0.25 \mathrm{~V}$ was studied under stirring at $300 \mathrm{rpm}$ in $\mathrm{ABS}$ of $\mathrm{pH}$ 4. The PAMAM/AgNPs-MWCNTs/PNR-modified electrode showed a stepwise increase in the catalytic current with successive addition of AA in the concentration range of 3.32 to $32.25 \mu \mathrm{M}$. Figure $8 \mathrm{~B}$ shows the calibration plot with a linear relationship between catalytic current and concentration of AA in a linear range of 3.32 to $32.25 \mu \mathrm{M}$ with a correlation coefficient of 0.9958 .

\subsection{Reproducibility and interference tests}

PAMAM/AgNPs-MWCNTs/PNR-modified electrode towards AA in the presence of interfering analytes such as gallic acid (GA), L-Tryptophan (L-Try), riboflavin (RF) and butylated hydroxyanisole (BHA) was studied. Amperometric response to the detection of AA at PAMAM/AgNPsMWCNTs/PNR-modified electrode in the presence of abovementioned interference in ABS of $\mathrm{pH} 4$ was also observed. The interference was selected based upon their presence in various commercial samples. The effect of the possible interfering substances on the response of the sensor was evaluated at the fixed potential of $0.25 \mathrm{~V}$. Figure 9 shows that the first three additions of $15 \mu \mathrm{M}$ of AA showed a gradual increase, but the fourth addition of each $60 \mu \mathrm{M}$ (1:4 ratio) of GA, L-Try, RF and BHA solution caused no significant interference in the response of the sensor. This result showed that the PAMAM/AgNPs-MWCNTs/PNRmodified electrode was highly selective towards the oxidation of AA.
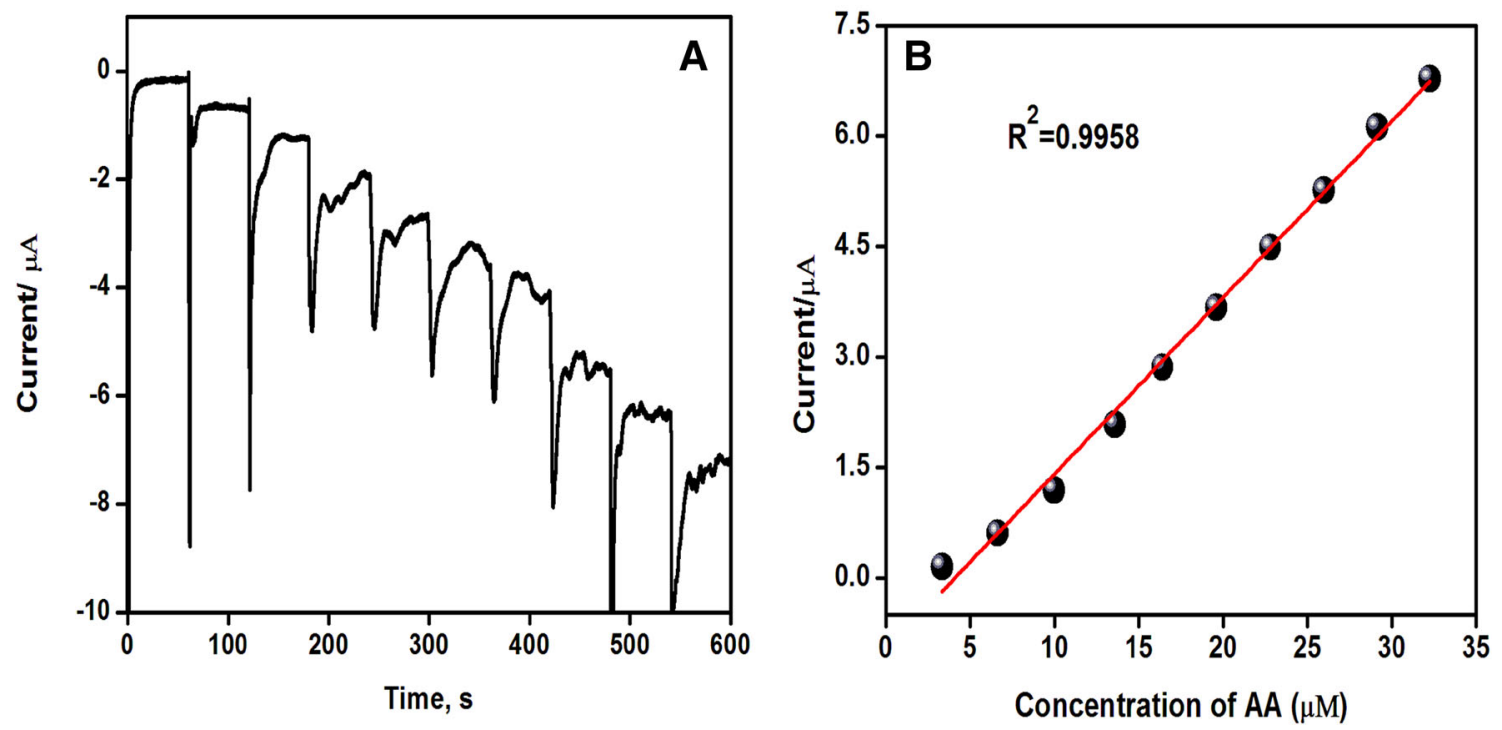

Figure 8. (A) Chronoamperometric responses of the PAMAM/AgNPs-MWCNTs/PNR-modified electrode for the successive additions of $0.2 \mathrm{ml}$ of $0.001 \mathrm{M}$ stock solution of AA in $60 \mathrm{ml}$ of $0.1 \mathrm{M} \mathrm{ABS}$ of pH 4 , at a scan rate of $50 \mathrm{mV} \mathrm{s}^{-1}$, and the applied potential of $0.25 \mathrm{~V}$ with a stirring rate of $300 \mathrm{rpm}$. (B) The corresponding calibration plot in the range of $3.32-32.25 \mu \mathrm{M}$. 


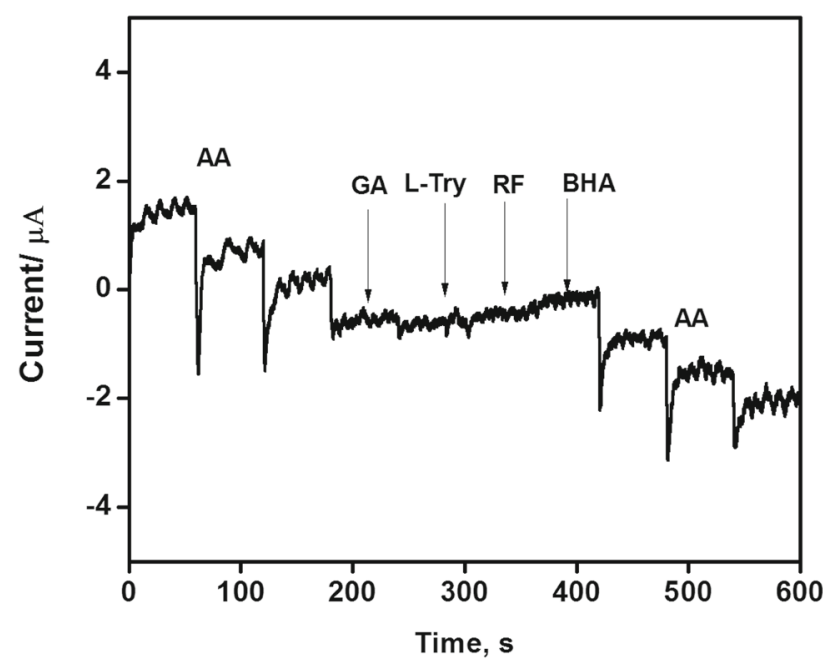

Figure 9. Amperometric response of the PAMAM/AgNPsMWCNTs/PNR-modified electrode towards interference effect in the determination of AA in the presence of various interferents in $0.1 \mathrm{M} \mathrm{ABS}$ of $\mathrm{pH} 4.0$ at a peak potential of $0.25 \mathrm{~V}$ with a stirring rate of $300 \mathrm{rpm}$.

\subsection{Long time stability of the}

PAMAM/AgNPs-MWCNTs/PNR-modified electrode for AA determination

In order to assess shelf life of PAMAM/AgNPs-MWCNTs / PNR-modified electrode response at an interval of 5 days towards $81.5 \mu \mathrm{M}$ AA studies for a period of 60 days showed that the proposed modified electrode retained $94 \%$ response at the end (figure 10A). The operating long-time stability of PAMAM/AgNPs-MWCNTs/PNR-modified electrode was analysed by injecting $81.5 \mu \mathrm{M}$ AA every 30 min over an extended period of $7 \mathrm{~h}$ (figure 10B). There is no significant change observed during this period. The above results indicate that the PAMAM/AgNPs-MWCNTs/PNR-modified electrode has both good storage capacity and operational stability as an amperometric sensor.

\subsection{Analysis of pharmaceutical and fruit samples}

The analytical application of the PAMAM/AgNPsMWCNTs/PNR-modified electrode for the determination of AA was analysed by measuring the concentration of AA in commercially available tablets and fruit samples (lemon and orange juices). The vitamin $\mathrm{C}$ tablet powder samples were diluted with DD water and two different volumes of each sample were added to $50 \mathrm{ml}$ of ABS ( $\mathrm{pH} \mathrm{4.0).} \mathrm{Before}$ the test, the fruit juice samples were diluted with $0.1 \mathrm{M}$ ABS ( $\mathrm{pH} \mathrm{4.0)} \mathrm{at} \mathrm{an} \mathrm{appropriate} \mathrm{volume} \mathrm{ratio.} \mathrm{DPV} \mathrm{was}$ employed for the determination of AA. The evaluation of the AA concentration is carried out using a standard addition method. The recovery and relative standard deviation (RSD) values have been tabulated from the analysis (table 2). The results illustrate that the PAMAM/AgNPs-MWCNTs/PNRmodified electrode can be utilized for the real sample analysis.
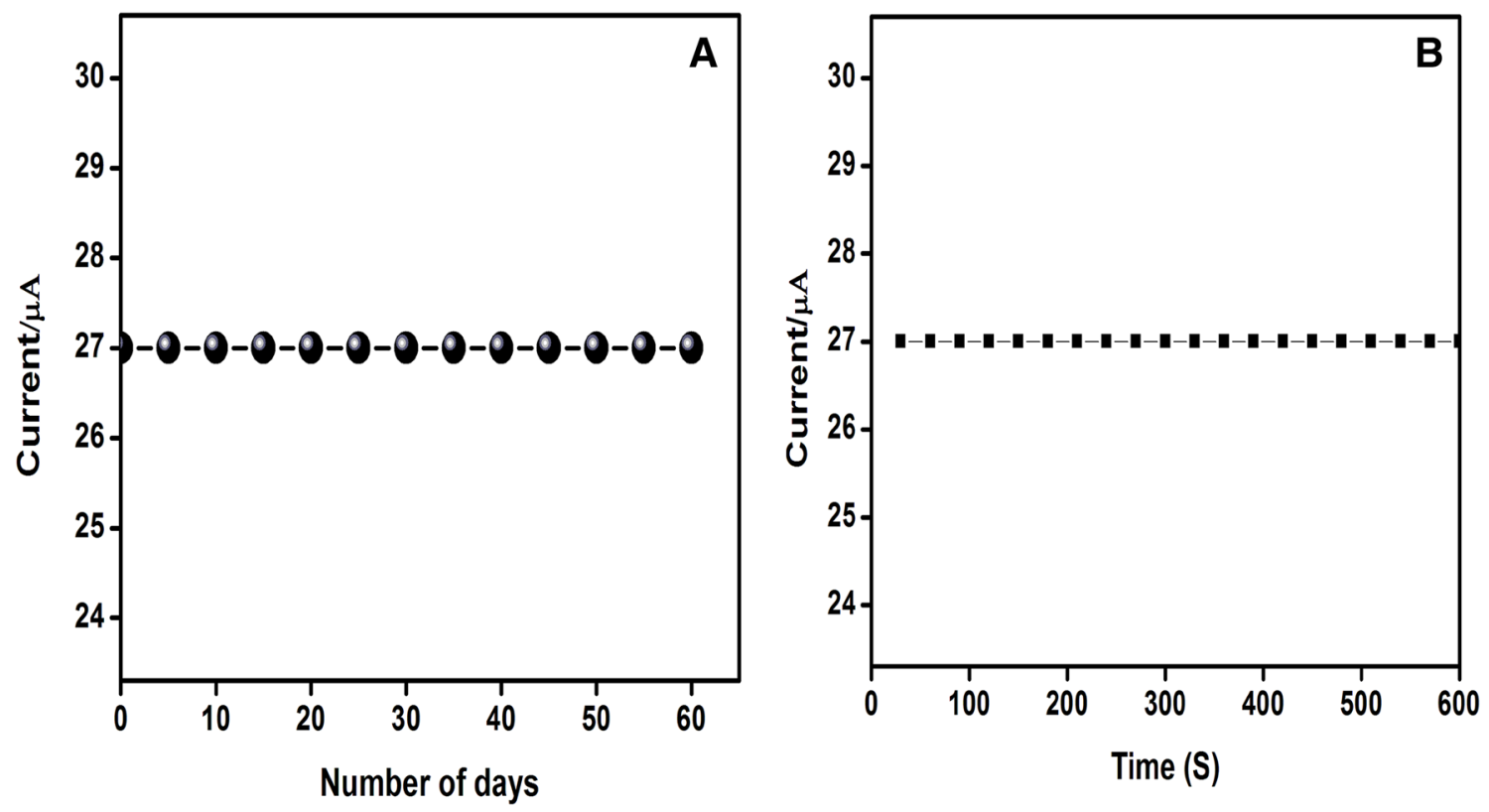

Figure 10. (A) Long time stability response of the PAMAM/AgNPs-MWCNTs/PNR-modified electrode towards the oxidation of AA $(81.6 \mu \mathrm{M})$. (B) Current response of the PAMAM/AgNPs-MWCNTs/PNR-modified electrode for AA $(81.6 \mu \mathrm{M})$ various times. 
Table 2. Determination of AA in vitamin $\mathrm{C}$ tablets and fruit juices.

\begin{tabular}{lrrrr}
\hline Samples & Added $(\mu \mathrm{M})$ & Found $(\mu \mathrm{M})$ & $\begin{array}{c}\text { RSD } \\
(\%)\end{array}$ & $\begin{array}{r}\text { Recovery } \\
(\%)\end{array}$ \\
\hline $\begin{array}{l}\text { Vitamin } \\
\quad \text { C tablets }\end{array}$ & 5 & $5.32( \pm 0.04)$ & 0.891 & 106.4 \\
2 & 10 & $10.16( \pm 0.11)$ & 0.873 & 101.6 \\
$\begin{array}{l}\text { Fruit juices } \\
\quad \text { Lemon }\end{array}$ & 10 & $10.08( \pm 0.09)$ & 1.07 & 100.8 \\
$\quad$ Orange & 20 & $20.10( \pm 0.03)$ & 0.98 & 100.5 \\
\hline
\end{tabular}

Source: Average three repeated measurements ( \pm standard deviation).

\section{Conclusions}

A highly stable PAMAM/AgNPs-MWCNTs/PNR filmmodified electrode was fabricated successfully by electropolymerization of NR over PAMAM/AgNPs-MWCNTs electrode. The resulting PAMAM/AgNPs-MWCNTs/PNRmodified electrode was characterized by scanning electron microscopy and CV. Furthermore, the PAMAM/AgNPsMWCNTs/PNR-modified electrode was investigated for use in the electrocatalytic oxidation of AA. The PAMAM/ AgNPs-MWCNTs/PNR-modified electrode was found to be highly stable, selective and sensitive towards the determination of AA. The proposed PAMAM/MWCNTs-AgNPs/PNR film-modified electrode has shown a high determination range of 0.16 to $2500 \mu \mathrm{M}$. The PAMAM/AgNPs-MWCNTs/PNRmodified electrode is also used for AA determination in real samples.

\section{Acknowledgements}

The authors gratefully acknowledge the DST-Inspire fellowship from the Department of Science and Technology, New Delhi, India for financial assistance.

\section{References}

[1] Wang X, Wu P, Hou X and Lv Y 2013 Analyst 138229

[2] Wu G H, Wu Y F, Liu X W, Rong M C, Chen X and Chen X 2012 Anal. Chim. Acta $\mathbf{7 4 5} 33$

[3] Luo X L, Xu J J, Zhao W and Chen H Y 2004 Anal. Chim. Acta 51257

[4] Andreu Y, Marcos S, Castillo J R and Galban J 2005 Talanta 651045

[5] Anastos N, Barnett N W, Hindson B J, Lenehan C E and Lewis S W 2004 Talanta 64130

[6] Nováková L, Solichová D and Solich P 2009 J. Chromatogr. A 12164574
[7] Suntornsuk L, Gritsanapun W, Nilkamhank S and Paochom A 2002 J. Pharm. Biomed. Anal. 28849

[8] Saari N B, Osman A, Selamat J and Fujita S 1999 Food Chem. 6657

[9] Qiu S, Gao S, Liu Q, Lin Z, Qiu B and Chen G 2011 Biosens. Bioelectron. 264326

[10] Chairam S, Sriraksa W, Amatatongchai M and Somsook E 2011 Sensors 1110166

[11] Senel M and Çevik E 2012 Curr. Appl. Phys. 121158

[12] Durst R A, Baumner A J, Murray R W, Buck R P and Andrieux C P 1997 Pure Appl. Chem. 691317

[13] Ran X Q, Yuan R, Chai Y Q, Hong C L and Qian X Q 2010 Colloids Surf. B Biointerfaces 79421

[14] Lopez J A, Manriquez J, Mendoza S and Godınez L A 2007 Electrochem. Commun. 92133

[15] Jeykumari S, Ramaprabhu S and Sriman Narayanan S 2007 Carbon 451340

[16] Torigoe K, Suzuki A and Esumi K 2001 J. Colloid Interface Sci. 241346

[17] Ramírez-Segovia A S, Banda-Alemán J A, Gutiérrez-Granados S, Rodríguez A, Rodríguez F J, Godínez A et al 2014 Anal. Chim. Acta $\mathbf{8 1 2} 18$

[18] Zhang Y, Ying Xu M and Kun Jiang T 2014 Chin. Chem. Lett. 25815

[19] Lee S H, Teng C C, Ma C C and Wang I 2011 J. Colloid Interface Sci. 3641

[20] Cui H, Zou G Z and Lin X Q 2003 Anal. Chem. 75324

[21] Scholz F and Lange B 1992 Tr. Anal. Chem. 11359

[22] Yang C M, Yi J L, Tang X J, Zhou G Z and Zeng Y 2006 React. Funct. Polym. 661336

[23] Ghica M E and Brett C M A 2006 Electroanalysis 18748

[24] Yogeswaran U and Chen S M 2007 Electrochim. Acta 52 5985

[25] Carvalho R C, Caridade C G and Brett C M A 2010 Anal. Bioanal. Chem. 3981675

[26] Purushothama H T and Arthoba Nayaka Y 2017 Sens. BioSens. Res. 1612

[27] Manjunatha P, Nayaka Y A, Chethana B K, Vidyasagar C C and Yathisha R O 2018 Sens. Bio-Sens. Res. 177

[28] Huang J S, Liu Y, Hou H Q and You T Y 2008 Biosens. Bioelectron. 24632

[29] Yang L, Liu D, Huang J and You T 2014 Sens. Actuators B 193 166

[30] Yan J, Liu S, Zhang Z, He G, Zhou P and Liang H 2013 Colloids Surf. B Biointerfaces 111392

[31] Jiang J and Du X 2014 Nanoscale 611303

[32] Han D, Han T, Shan C, Ivaska A and Niu L 2010 Electroanalysis 222001

[33] Liu X, Ou X, Lu Q, Zhang J, Chen S and Wei S 2014 RSC Adv. 442632

[34] Zheng X, Zhou X, Ji X, Lin R and Lin W 2013 Sens. Actuators B Chem. 178359

[35] Li S J, Qian C, Wang K, Hua B Y, Wang F B, Sheng Z H et al 2012 Sens. Actuators B 174441

[36] Rafati A A, Afraz A, Hajian A and Assari P 2014 Microchim. Acta 1811999 